\begin{tabular}{|c|l|}
\hline Title & A novel biotinylated diazirinyl ceramide anal ogue for photoaffinity labeling \\
\hline Author(s) & Hashimoto, Makoto; Hatanaka, Y asumaru \\
\hline Citation & $\begin{array}{l}\text { Bioorganic \& Medicinal Chemistry Letters, 18(2), 650-652 } \\
\text { https:/doi.org/10.1016/.bmcl.2007.11.071 }\end{array}$ \\
\hline Issue Date & 2008 -01-15 \\
\hline Doc URL & http://hdl.handle.net/2115/64917 \\
\hline Rights & ○ 2007 Elsevier Ltd \\
\hline Type & article (author version) \\
\hline File Information & 21 BMCL 18650-652-1.pdf \\
\hline
\end{tabular}

Instructions for use 


\title{
A novel biotinylated diazirinyl ceramide analogue for photoaffinity labeling
}

\author{
Makoto Hashimoto, ${ }^{a, *}$ and Yasumaru Hatanaka ${ }^{b}$ \\ ${ }^{a}$ Department of Agricultural and Life Science, Obihiro University of Agriculture and Veterinary Medicine, Inada-cho, \\ Obihiro 080-8555, Hokkaido, Japan \\ ${ }^{b}$ Faculty of Pharmaceutical Sciences, Toyama University, 2360 Sugitani, Toyama, 930-0194 Japan
}

This is where the receipt/accepted dates will go; Received Month XX, 2007; Accepted Month XX, 2007 [BMCL RECEIPT]

\begin{abstract}
A novel photoreactive ceramide analogue, which contains (3-trifluoromethyl) phenyldiazirinyl lipid and biotinylated sphingosine, was synthesized. The probe was recognized as an antigen by anti-ceramide antibody and as a substrate for sphingolipid ceramide N-deacylase. These results indicate that the probe may be useful as a photoaffinity-biotinylating agent in sphingolipid studies. [BMCL ABSTRACT] C2000 Elsevier Science Ltd. All rights reserved.
\end{abstract}

Research into glycosphingolipids have been attracting increasing attention recently because they are closely involved in cell adhesion, and the regulation of cell growth and differentiation. ${ }^{1,2}$ They consist of a hydrophilic sugar moiety and hydrophobic ceramide.

Although many investigations have reported the biological roles of sugar moieties, there is little information on those of the ceramide moiety in glycosphingolipids.

Photoaffinity labeling is a useful biochemical method to reveal structural and functional relationships between low molecular weight bioactive compounds and biomolecules. $^{3}$ The method is suitable for analyzing biological interactions because it is based on the affinity of bioactive compounds for biomolecules. Various photophores, such as phenyldiazirine, arylazide and benzophenone, are used. ${ }^{4}$ Although comparative irradiation studies of these three photophores in living cells indicated that a carbene precursor (3trifluoromethyl)phenyldiazirine is the most promising photophore, ${ }^{4}$ the rather complicated synthesis of the (3trifluoromethyl)phenyldiazirinyl three-membered ring has resulted in fewer applications in biomolecular studies than other photophores. Furthermore, the low cross-linking yield of photoaffinity labeling experiments still hampers the purification and isolation of labeled components. ${ }^{5}$ We have attempted to solve these difficulties by using the combinational introduction of a diazirinyl photophore and an avidin-biotin system (photoaffinity biotinylation). ${ }^{6-9}$ In this paper, we describe a novel photoreactive ceramide analogue for use in photoaffinity biotinylation of glycosphingolipidrelated biomolecules.

Several diazirine-based photoreactive ceramide ${ }^{10-13}$ or glycosphigolipid $^{14-16}$ analogues have been reported, but they have no tag or radiolabeled iodine on the benzene ring to detect photolabeled components. This is not an easy method to handle radiolabeled compounds for organic synthesis.

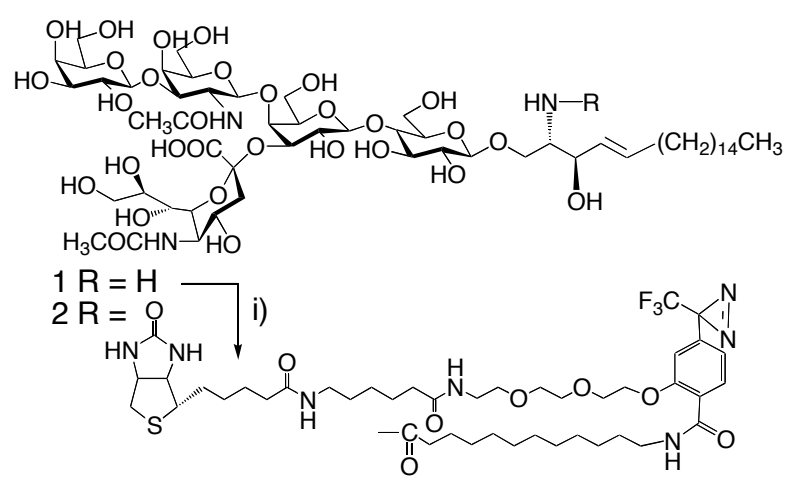

Figure 1. Synthesis of biotinylated diazirinyl GM1 derivative 2 . i) 3 (2 R-OSu), triethylamine, DMF, rt, 8 h, 65\%. 
For photoaffinity biotinylation we attempted to introduce a biotinylated diazirinyl fatty acid $N$ hydroxysuccinimide ester $\mathbf{3}$ to lyso GM1 $\mathbf{1}$ to give a photoreactive GM1 analogue $\mathbf{2}$ in moderate yield. Compound 2 was assayed using Pseudomonas sp. sphingolipid ceramide $N$-deacylase (SCDase), which generates sphingosine and fatty acids from the ceramide moiety of sphingolipids, ${ }^{17-20}$ but unfortunately, the photoreactive GM1 analogue $\mathbf{2}$ was not a substrate recognized by the enzyme. We therefore had to establish new concepts applying photoaffinity biotinylation to SCDase.

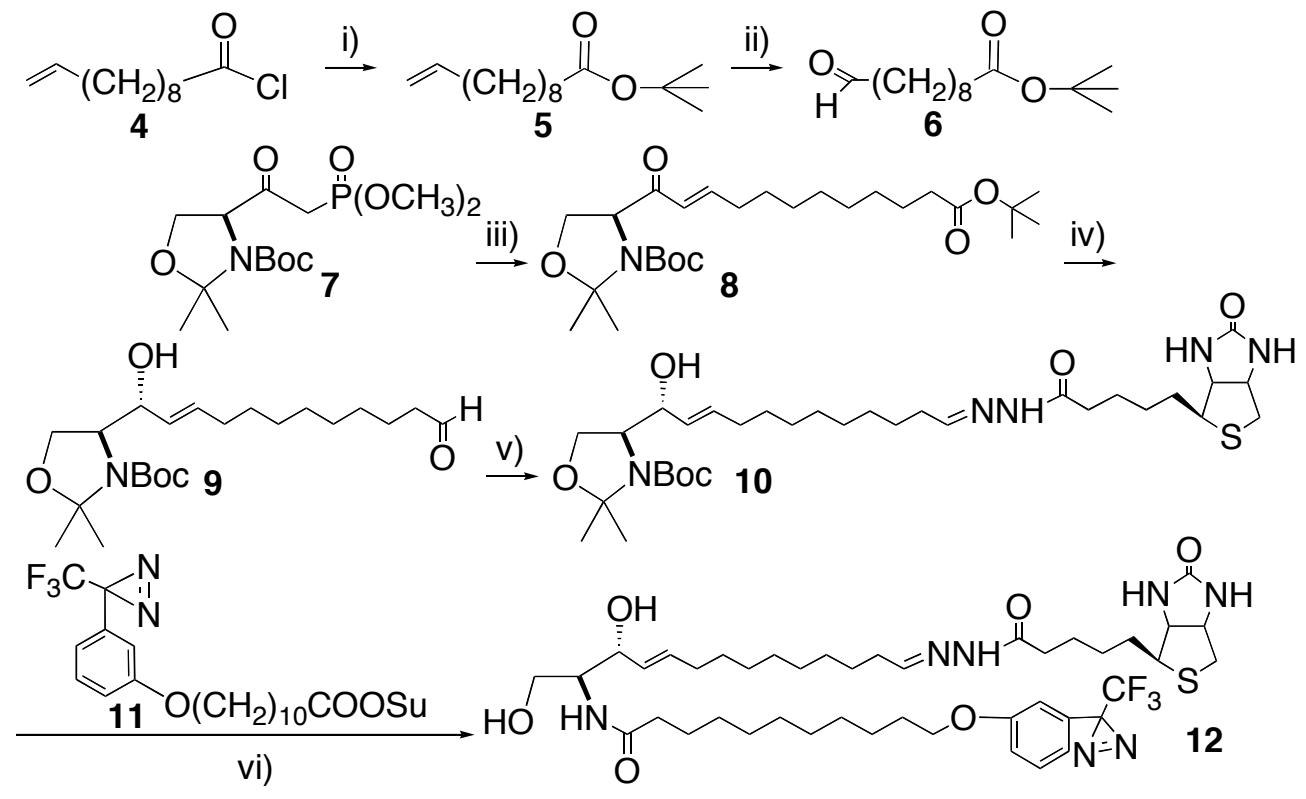

Figure 2. Synthesis of bifuctional ceramide derivatives 12. i) tert-butanol, TEA, rt, $2 \mathrm{~h}(91 \%)$, ii) $\mathrm{OsO}_{4}, \mathrm{NaIO}_{4}$, Dioxane, $\mathrm{H}_{2} \mathrm{O}, \mathrm{rt}, 1 \mathrm{~h}(60 \%)$, iii) 6, $\mathrm{K}_{2} \mathrm{CO}_{3}$, $\mathrm{CH}_{3} \mathrm{CN}, \mathrm{rt}, 12 \mathrm{~h}\left(72 \%, 93 \%\right.$ ee), iv) DIBAL-H, toluene, $-70{ }^{\circ} \mathrm{C}, 1 \mathrm{~h}(67 \%$, syn : anti $=1: 6)$, v) biotin hydrazide, DMF, rt, $12 \mathrm{~h}(93 \%)$, vi) $50 \% \mathrm{TFA}$, $\mathrm{CH}_{2} \mathrm{Cl}_{2}$, then, 11, $\mathrm{CHCl}_{3} \mathrm{CH}_{3} \mathrm{OH}$, TEA, rt, 3h (50\%).

SCDase recognized not only sphingolipids but also ceramide, which is composed of fatty acid and $D_{D}$-erythro sphingosine. We introduced a photoreactive group and biotin to fatty acid and D-erythro sphingosine, respectively.

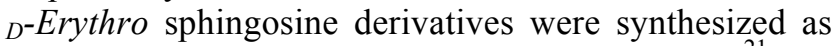
reported by Koskinen, with slight modifications. ${ }^{21} 10$ Undecenoyl chloride 4 was converted to tert-butyl ester $\mathbf{5}$, followed by conversion to aldehyde $\mathbf{6}$ by oxidation of olefin with sodium periodate and $\mathrm{OsO}_{4}$ in moderate yield. Trans-selective double bond formation with compound $\mathbf{6}$ and $\beta$-ketophosphonate 7 was achieved by a modified Horner-Wadsworth-Emmons reaction with $\mathrm{K}_{2} \mathrm{CO}_{3}$ in $\mathrm{CH}_{3} \mathrm{CN}$. Enone reduction of $\mathbf{8}$ with DIBAL-H in toluene gave anti-diastereomer 9 as the main product. The terminal aldehyde was converted to Schiff base $\mathbf{1 0}$ with biotinhydrazide. After acid deprotection, diazirinyl fatty acid $N$-hydroxysuccinimide ester $11^{5}$ was introduced to give biotinylated diazirinyl ceramide derivative $12^{22}$. Several sphingolipids have antigenic activities that are used to detect the localization of these compounds in the cell. ${ }^{23} \mathrm{We}$ examined whether photoreactive ceramide analogue 12 was recognized by mouse anti-ceramide antibody. The synthetic ceramide analogue was developed on TLC. The developed sphingolipid was transferred to PVDF membrane (farEastern blotting) as reported in the literature. ${ }^{24}$

\section{lane $\quad 1 \quad 2$}

Figure 3. Immunochemical detection of compound $\mathbf{1 2}$ with StreptavidinHRP (for biotin, lane 1) and mouse anti-ceramide antibody (for ceramide skeleton, lane 2). Compound 12 was developed on silica-TLC $\left(\mathrm{CHCl}_{3}\right.$ : $\mathrm{CH}_{3} \mathrm{OH}=9: 1$ ), and then the TLC was subjected to far-Eastern blotting on a PVDF membrane. ${ }^{23}$ The membrane was treated for chemiluminescence detection as described previously. ${ }^{24}$

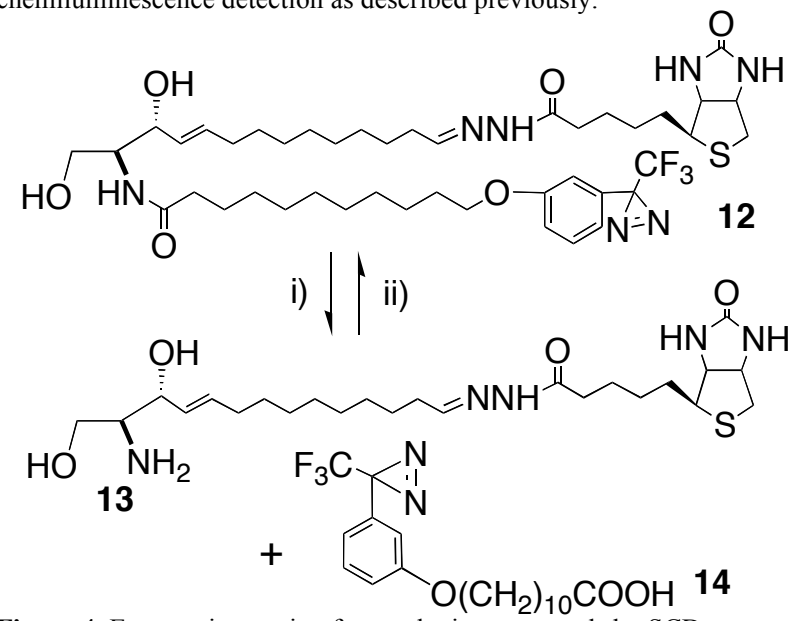

Figure 4. Enzymatic reaction for synthetic compounds by SCDase i) $0.8 \%$ Triton X-100, $50 \mathrm{mM}$ sodium acetate buffer, $\mathrm{pH} 6.0,37^{\circ} \mathrm{C}, 12 \mathrm{~h}$, $86 \%$, ii) $0.1 \%$ Triton X-100, $25 \mathrm{mM}$ sodium phosphate buffer, $\mathrm{pH} 7,48 \mathrm{~h}$, $25 \%$, 
The membrane was subjected to two immunodetection methods.

The first method was treatment with streptavidinhorseradish peroxidase (HRP) conjugate to detect the biotin component. As the second method, we used mouse anti-ceramide antibody and subsequently goat anti-mouse IgM-HRP conjugate to detect the ceramide skeleton. Both treatments then used chemiluminescence reagents to detect the immune complex (Fig. 3 lanes 1 and 2, respectively). Both detection methods gave a chemiluminescence signal in the same position on TLC. The result indicated that the synthetic ceramide derivative 12 was recognized by both streptavidin and the mouse anti-ceramide antibody without dissociation of the Schiff base moiety.

Enzymatic reaction of compound $\mathbf{1 2}$ resulted in

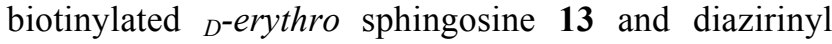
fatty acid derivatives $\mathbf{1 4}$ under hydrolyzed conditions by SCDase. In contrast, compounds 13 and 14 were condensed to $\mathbf{1 2}$ under reverse reaction conditions by SCDase (Fig. 4). ${ }^{17-20}$ It is therefore evident that SCDase recognized compound $\mathbf{1 2}$ as a substrate.

Photoaffinity labeling of SCDase with compound $\mathbf{1 2}$ was performed under hydrolysis conditions. The enzyme was incubated briefly with excess photoligand, and then the mixture was irradiated with a black light lamp $(15 \mathrm{~W})$ at $0^{\circ} \mathrm{C}$ for $20 \mathrm{~min}$. Competitive inhibition was performed in the presence of an excess amount of ganglioside mixtures as the natural substrate. The irradiated samples were subjected to SDS-PAGE followed by Western blotting to detect the labeled components by chemiluminescence as described previously. ${ }^{25}$ The chemiluminescence signal was detected in a substance of the reported molecular weight of SCDase (52 KDa) (Fig. 5, lane 1). Competitive inhibition of photoaffinity biotinylation was observed in the presence of the ganglioside mixtures (Fig. 5, lane 2); therefore, compound $\mathbf{1 2}$ was incorporated in the binding site of the natural substrates.

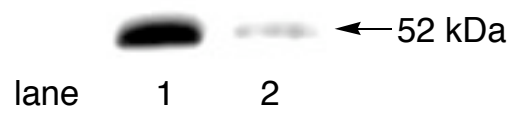

Figure 5. Chemiluminescence detection of photoaffinity labeled SCDase with compound 12. Labeled proteins without (lane 1) or with (lane 2) excess ganglioside mixtures (Sigma G-2375) were subjected to SDSPAGE $(10 \%)$, followed by transfer to a PVDF membrane to detect the biotin moiety.

Sphingolipids have been studied recently because they are highly enriched intracellularly in the cell membrane of most mammalian cells. ${ }^{1,2}$ The compartmentalization of sphingolipids in membranes serves as the starting pool for sphingolipid metabolism. All metabolites of sphingolipids presumably function either as intercellular secondary messengers or as ligand molecules for cell surface receptors. Ceramide biosynthesized from dihydroceramide and sphingomyelin is well known as the precursor for sphingoshine-1-phosphate, which is a member of the lysophospholipid growth factor family; however, there have been few reports on the structureactivity relationships of fatty acid and sphingosine moieties, due to the difficulty of obtaining their derivatives. This is the first report, to our knowledge, of the synthesis of a bifunctional ceramide analogue, and will help to elucidate the functions of sphingolipids.

\section{Acknowledgements}

This research was supported partly by Grants-in-Aid for Scientific Research on a Priority Area, 18032007, and for Scientific Research (C), 19510210 from the Ministry of Education, Science, Sports and Culture (to M.H.). M.H. also thanks the Fugaku Foundation and Research for Promoting Technological Seeds for financial support for the study.

\section{References and Notes}

1. Butters, T. D.; Dwek, R. A.; Platt, F. M. Chem. Rev. 2000, 100, 4683.

2. Liao, J.; Tao, J.; Lin, G.; Liu, D. Tetrahedron 2005, 61, 4715.

3. Brunner, J. Annu. Rev. Biochem. 1993, 62, 483.

4. Gillingham, A. K.; Koumanov, F.; Hashimoto, M.; Holman, G. D. Detection and analysis of glucose transporters using photolabelling techniques. in Membrane transport : A Practical Approach;, Baldwin S. A. Eds.; Oxford University Press: Oxford, 2000; pp193.

5. Hatanaka, Y.; Nakayama, H.; Kanaoka, Y. Rev. Heteroatom Chem. 1996, 14, 213.

6. Tomohiro, T.; Hashimoto M.; Hatanaka, Y. Chem. Records 2005, 5, 385.

7. Hatanaka, Y.; Hashimoto, M.; Kanaoka, Y. Bioorg. Med. Chem. 1994, 2, 1367.

8. Hatanaka, Y.; Hashimoto, M.; Kanaoka, Y. J. Am. Chem. Soc. 1998, 120, 453 .

9. Hashimoto, M.; Yang, J.; Holman, G. D. ChemBioChem 2001, 2, 52.

10. Weber, T.; Brunner, J. J. Am. Chem. Soc. 1995, 117, 3084.

11. Li, G.; Bittman, R. Tetrahedron Lett. 2000, 41, 6737. 12. Shigenari, T.; Hakogi, T.; Katsumura, S. Chem. Lett. 2004, 33, 594.

13. Yamamoto, T.; Hasegawa, H.; Hakogi, T.; Katsumura, S. Org. Lett. 2006, 8, 5569.

14. Meier, E. M.; Schummer, D.; Sandhoff, K. Chem. Phys. Lipids 1990, 55, 103.

15. Hashimoto, M.; Hatanaka, Y.; Nabeta, K. Bioorg. Med. Chem. Lett. 2002, 12, 89.

16. Hashimoto, M.; Hatanaka, Y. Chem. Pharm. Bull. 2004, 52, 1385 .

17. Ito, M.; Kurita, T.; Kita, K. J. Biol. Chem. 1995, 270 , 24370-24374.

18. Mitsutake, S.; Kita, K.; Okino, N.; Ito, M. Anal. 
Biochem. 1997, 247, 52.

19. Ito, M.; Mitsutake, S; Tani, M.; Kita, K. Methods Enzymol. 1999, 311, 682.

20. Kita, K.; Kurita, T.; Ito, M. Eur. J. Biochem. 2001, 268, 592.

21. Koskinen, P. M.; Koskinen, A. R. P. Methods Enzymol. 1999, 311, 458.

22. compound 12 FAB-MS (negative) $m / z 864\left([\mathrm{M}-\mathrm{H}]^{+}\right)$; ${ }^{1} \mathrm{H}-\mathrm{NMR}\left(\mathrm{CDCl}_{3}\right) \delta 7.30(1 \mathrm{H}, \mathrm{t}, J=8.3 \mathrm{~Hz}), 6.92(1 \mathrm{H}, \mathrm{d}, J$ $=8.3 \mathrm{~Hz}), 6.75(1 \mathrm{H}, \mathrm{d}, J=8.3 \mathrm{~Hz}), 6.66(1 \mathrm{H}, \mathrm{s}), 5.72$ $(1 \mathrm{H}, \mathrm{m}), 5.51(1 \mathrm{H}, \mathrm{m}), 5.20(1 \mathrm{H}, \mathrm{m}), 4.52(\mathrm{dd}, 2 \mathrm{H}, J=7.6$, $4.9 \mathrm{~Hz}), 4.36(\mathrm{dd}, 2 \mathrm{H}, J=7.6,4.4 \mathrm{~Hz}), 3.90(2 \mathrm{H}, \mathrm{t}, J=6.4$ $\mathrm{Hz}), 3.36(\mathrm{~m}, 2 \mathrm{H}), 3.24(\mathrm{~m}, 1 \mathrm{H}), 2.97$ (dd, 1H, $J=12.9$,
$4.9 \mathrm{~Hz}), 2.74(\mathrm{~d}, 1 \mathrm{H}, J=12.9 \mathrm{~Hz}), 2.54(2 \mathrm{H}, \mathrm{m}), 2.33(\mathrm{~m}$, 2H), 1.80-1.20 (34H, m)

23. Benjamins, J. A.; Callahan, R. E.; Montgomery, I. N.; Studzinski, D. M.; Dyer, C. A. J. Neuroimmnol. 1987, 14, 325-338.

24. Ishikawa, D; Taki, T. Methods Enzymol. 2000, 312, 145.

25. Hatanaka, Y.; Hashimoto, M.; Nishihara, S.; Narimatsu, H.; Kanaoka, Y. Carbohydr. Res. 1996, 294, 95.

* Corresponding author. Tel.: +81-155-49-5542; Fax: +81-155-49-5577; e-mail: hasimoto@obihiro.ac.jp 